\title{
PROFILE OF THE BETEL/TOBACCO QUID CHEWERS IN SIX MALAYSIAN ESTATES
}

B.S. Tan, A. Rosman, K.H. Ng, N. Ahmad. Profile of the betel/tobacco quid chewers in six Malaysian estates. Annal Dent Univ Malaya 2000; 7: 1-5.

\section{ABSTRACT}

The aim of the study was to determine the characteristics and pattern of the betel /tobacco quid chewing habit in the estate Indian community. The study was conducted in 6 randomly selected estates. It involved oral mucosal examination and an interview to solicit personal data as well as history and details of oral habits

Of a total of 618 subjects studied, $19.3 \%(n=119$; 89 females and 30 males) were betel /tobacco quid chewers. The youngest age of onset of betel quid chewing is 10 years. The mean frequency of chewing quid is 4.3 times/day and the mean duration of chewing is 8.1 minutes.

Initiation to the habit occur at a young age and a major role is played by family and friends in initiation to the habit. Practises of adding tobacco and lime appear to have adverse effects and are associated with higher occurrences of precancer lesions in this study $(p<0.05)$.

Key words: betel quid, tobacco quid, oral cancer, estate Indian

\section{INTRODUCTION}

The term "quid" is defined as a substance or mixture of substances, placed in the mouth for long topical contact with the mucosa and containing, for example, one of the two basic ingredients, tobacco and/or areca nut, in raw or any manufactured or processed form. In this study, "betel quid" was considered a specific variety of quid to indicate any type of mixture or quid taken along with betel leaf. "Tobacco quid" is quid with tobacco products (1).

The association of betel quid chewing with tobacco and oral cancer is now well recognised (2-7) and the use of tobacco and the habit of betel chewing has been associated with the high prevalence of oral precancerous lesions and oral carcinomas in India and Southeast Asia $(8-12)$

Betel quid chewing is a traditional custom seen in both Indian and Malay culture and occupies the same position that smoking does in Western countries (13). Many Malaysian studies on oral cancer and precancer (14-15), including the recent adult nation-wide survey on oral mucosal lesions in Malaysia (16) had shown a high prevalence amongst the Indian population. Several epidemiological studies on oral mucosal lesions, including oral precancerous and cancerous lesions have
Original Article

B.S. Tan' 1 A. Rosman', K.H. Ng${ }^{1}$ and
N. Ahmad
1Division of Stomatology, and
2Division of Human Nutrition
Institute for Medical Research
Jalan Pahang
50588 Kuala Lumpur
Malaysia.
Corresponding author - B.S. Tan

been conducted locally. Few studies on chewing and other oral habits in relation to oral cancer are available. Oral cancer associated with betel chewing is the common form of oral cancer in this country and racial variations in the pattern of risk habits and carcinoma are evident (17).

There is a need to determine the characteristics of the chewing habits or describe the ingredients in detail to further identify whether the high prevalence of oral mucosal lesions is related to any particular feature of the risk habit.

The aim of this study was to describe the characteristics and pattern of the betel / tobacco quid chewing habit in the Malaysian estate Indian population.

\section{MATERIALS AND METHODS}

Six estates in Peninsula Malaysia (one each in Selangor, Malacca, Johore, and Pahang, and two in Negeri Sembilan) were randomly selected. Subjects were adults above 20 years of age invited to attend an oral examination. The respondents were interviewed to obtain information on oral risk habits of smoking, betel and or tobacco chewing and consumption of alcoholic beverages. This was followed by an oral mucosal examination to screen for oral precancer and oral cancer lesions. This was conducted by two examiners, the first author and the gold standard, the consultant oral pathologist. Cases detected by the first author were referred to and confirmed by the the gold standard.

A subject was considered to have a habit if he admits to being currently indulging in the habit, on a regular basis, regardless of frequency, for the past 3 months. The "ex" status was given when habit cessation exceeds 3 months

In this study, "betel quid" was defined as the preparation with the betel leaf as the basic constituent to which various substances may be added such as areca nut, slaked lime, tobacco, gambir etc.; and "tobacco 
quid" chewing is the consumption purely of tobacco as a chewed preparation.

\section{RESULTS}

The sample consisted of 618 adult respondents. The ethnic breakdown were as follows: 410 Indians, 189 Malays, 18 Chinese and 1 of other ethnic origin. There were 277 males and 341 females. The age range was 20 to 85 years and the mean age was $44.5 \pm 12.4$ overall; $43.5 \pm 12.3$ for men and $46.1 \pm 12.3$ for women.

From the interview, 240 subjects were identified to have either currently or previously practised some form of oral habits; 234 (37.9\%) had current habit(s). This included $113(18.3 \%)$ subjects with the smoking habit, $61(9.9 \%)$ subjects reporting the habit of alcohol consumption and $119(19.3 \%)$ subjects with betel quid/ tobacco chewing habit.

This paper will be focused on the betel quid and/ or tobacco chewing habit.

One hundred nineteen subjects were current and nine subjects reportedly were ex-chewers. The overall prevalence of the chewing habit was 119(19.3\%); of these 114 chew betel quid and 5 chew tobacco quid. The subjects consists of 30 males and 89 females.

The age range was $24-85$ years with a mean of 47.7 years. The age and gender distribution of the subjects are as shown in Table 1 .

Table 1. Age And Gender Distribution Of Chewers

\begin{tabular}{|c|c|c|c|c|c|}
\hline \multirow[t]{2}{*}{ Age } & \multirow[t]{2}{*}{ Overall } & \multicolumn{2}{|c|}{ Betel Quid } & \multicolumn{2}{|c|}{ Tobacco Quid } \\
\hline & & Male & Female & Male & Female \\
\hline $20-29$ & 4 & 0 & 4 & 0 & 0 \\
\hline $30-39$ & 27 & 4 & 21 & 0 & 2 \\
\hline $40-49$ & 45 & 9 & 35 & 1 & 0 \\
\hline $50-59$ & 23 & 8 & 14 & 1 & 0 \\
\hline $60-69$ & 11 & 5 & 6 & 0 & 0 \\
\hline $70-85$ & 9 & 1 & 7 & 1 & 0 \\
\hline Total & 119 & 27 & 87 & 3 & 2 \\
\hline
\end{tabular}

The age at which subjects first started their chewing habit ranged, from as early as 10 years to as late as 68 years. The mean age of onset of habit is 26.5 years. The age at which the highest number of subjects started the habit is 20 years.

Figure 1 shows the distribution of age of starting habit of the chewers by gender. The overall percentage distribution of subjects by age of onset of the chewing habit is shown in the pie chart in Figure 2. Out of the $32(27.8 \%)$ subjects whom age of onset of habit is less than 20 , twelve subjects $(10.1 \%)$ reportedly started chewing when they were less than 13 years old (primary school-going age) and twenty (16.8\%) subjects started

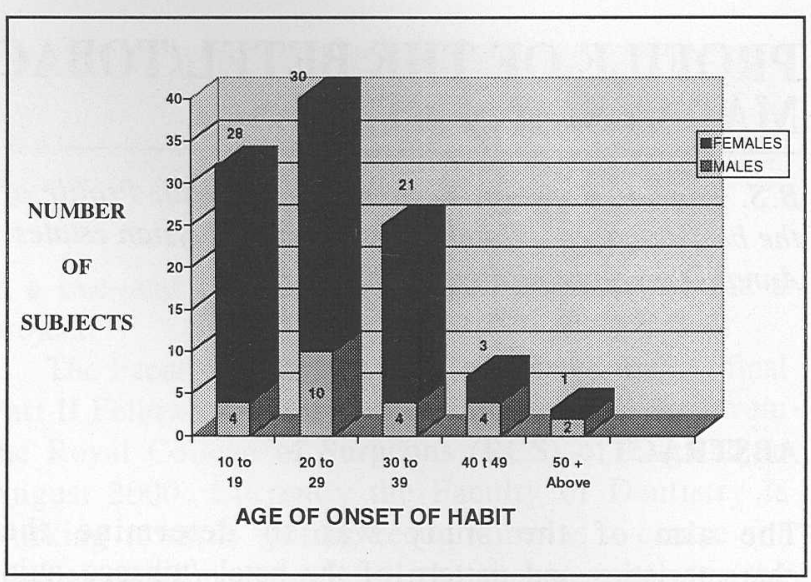

Figure 1: Distribution of chewers by age of onset of habit and gender

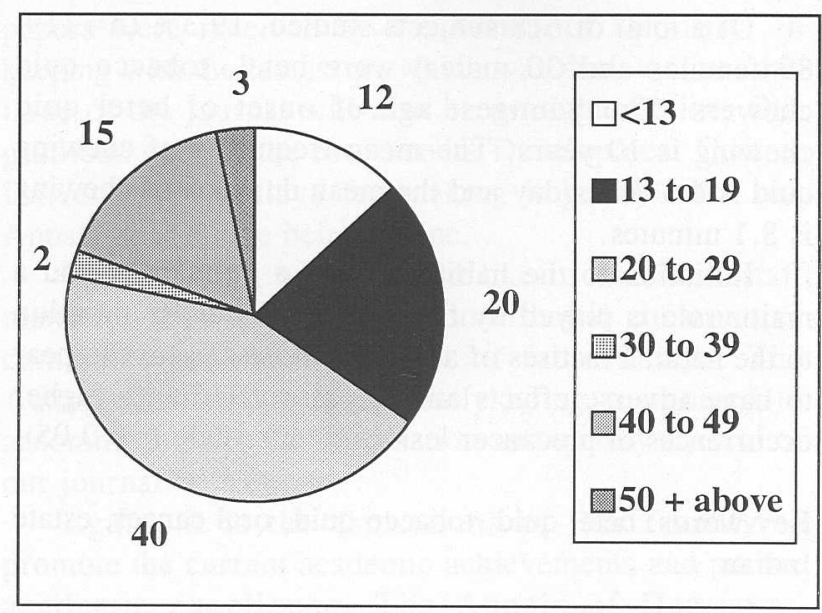

Figure 2: Overall distribution of chewers by age of onset

when they were between 13 and 19 years of age (corresponding to secondary school-going age).

Table 2 shows the reasons cited for starting and continuing the chewing habit. Subjects were allowed more than one responses from a list of possible reasons. The two most common reasons for starting the chewing habit were friends/curiosity $(61 ; 51.3 \%)$ and family members $(53 ; .44 .5 \%)$. On the other hand, reasons for continuing the habit were mainly habit $(72 ; 60.5 \%)$, pleasure $(70 ; 58.8 \%)$, good taste $(38 ; 31.9 \%)$ relaxation $(37.3 \%)$, increased work capacity $(27 ; 22.7 \%)$ and relaxation $(26 ; 21.8 \%)$.

The betel quid chewed by 114 subjects comprised varied combinations of areca nut, tobacco, betel leaf, lime and gambir. The 5 tobacco chewers chew only tobacco with no other constituents. The betel leaf is a constant component and is used in all 114 betel quid chewers. Lime, areca nut and tobacco are frequently added; $102(89.5 \%)$ subjects add lime to their quid, $98(86.0 \%)$ add areca nut and $69(60.5 \%)$ of subjects add tobacco. Gambir is added into the quid in $13(11.4 \%)$ subjects only. 
Table 2. Reasons for starting and or continuing the chewing habit

\begin{tabular}{lcc}
\hline Reasons & $\begin{array}{c}\text { Starting } \\
n\end{array}$ & $\begin{array}{c}\text { Continuing } \\
n\end{array}$ \\
\hline Advertisement & 0 & 0 \\
Boredom & 0 & 6 \\
Relaxation & 0 & 26 \\
Taste good & 1 & 38 \\
Family members & 53 & 10 \\
Cure bad breathe/toothache & 7 & 24 \\
Increased work capacity & 0 & 27 \\
Pleasure & 0 & 70 \\
Habit & 0 & 72 \\
Carminative, digestion, laxative, & & 1 \\
prevent nausea & 2 & 17 \\
Friends / curiosity & 61 & \\
\hline
\end{tabular}

Table 3. Frequency per day and Duration of Chews

\begin{tabular}{lrcr}
\hline & $\begin{array}{c}\text { Betel quid } \\
n=114\end{array}$ & $\begin{array}{c}\text { Tobacco Quid } \\
n=5\end{array}$ & \multicolumn{1}{c}{$\begin{array}{c}\text { All Chewers } \\
n=119\end{array}$} \\
\hline $\begin{array}{l}\text { Frequency } \\
\text { Range }\end{array}$ & $1-20$ times & $1-5$ times & $1-20$ times \\
Mean & 4.5 times & 3.4 times & 4.5 times \\
Median & 4.0 times & 3.0 times & 4.0 times \\
Duration: & & & \\
Range & $1-60$ minutes & $1-180$ minutes & $1-180$ minutes \\
Mean & 8.1 minutes & 44.0 minutes & 9.6 minutes \\
Median & 5.0 minutes & 10 minutes & 5.0 minutes \\
\hline
\end{tabular}

The frequency and duration of chewing betel quid and tobacco quid are shown in Table 3 . The frequencies of chewing betel quid ranged from 1 to 20 times per day, the mean frequency was 4.5 times. The duration of chews ranged from 1 to 60 minutes and the mean duration was 8.1 minutes. Tobacco quid chewing is carried out an average of 3.4 times per day (range: 1 to 5 times) for durations ranging from 1 to 180 minutes giving a mean duration of 44.0 minutes.
The common sites where the quid is placed during chewing are the left lower buccal sulcus $(n=77$; $64.7 \%)$, right lower buccal sulcus ( $n=34 ; 28.6 \%)$, right upper buccal sulcus $(n=4 ; 3.4 \%)$, left upper buccal sulcus $(n=1 ; 0.8 \%)$ and other sites $(n=3 ; 2.5 \%)$.

Table 4 shows the association of occurrence of precancer lesions with addition of various constituents to the quid (by the Chi Square test) and Table 5 shows the association of occurrence of precancer lesions with the mean age of onset, mean frequency and mean duration of chews (by t-test). The occurrence of precancer lesions is higher with the addition of areca, tobacco and lime and also with younger age of onset and more frequent chewing. In this study, the differences of higher occurrences of precancer lesions with additions of tobacco and lime to the quid are statistically significant ( $\mathrm{p}=0.03$ and 0.02 respectively).

\section{DISCUSSION}

The prevalence of betel quid chewers in this study is $18.5 \%$ and the overall prevalence for chewers (of betel and tobacco quids) is $19.25 \%$. This is higher than the finding $(7.0 \%)$ for the general Indian population reported by Zain et al., (16) and also higher than that in rural north Thailand (10) where a prevalence of $6.9 \%$ is quoted. However, this finding is lower compared to findings of studies conducted in the Bangladesh community in Yorkshire (95\%) (18), in India (37.7\% female, $13.7 \%$ male) (19), in Lahu (41.3\%) and Karen $(35.5 \%)$ tribes, Thailand (10) and in 9 Cambodian villages $(31.3 \%)(20)$.

The prevalence of the chewing habit was clearly lower in males $(\mathrm{n}=30 ; 10.8 \%)$ as compared to 89 $(26.2 \%)$ in females. This difference is statistically significant $(p<0.000)$ and is well in agreement with findings of other studies $(10,16,18,19,20,21)$.

The constituents of the quid differ from that of other population groups. The percentage of subjects who add constituents that are often reported to have deleterious effects in the quids such as areca, lime and tobacco are relatively smaller in the estate Indians in this study. In comparison, in the study in Yorkshire (18) areca is added in $97 \%$ of subjects, lime $90 \%$ and tobacco $60 \%$. The addition of tobacco is reportedly $65 \%$ in Cambodia (20) and $93.5 \%$ in Thailand (10). Warnakulasuriya (22) also reported that the percentage of subjects who chew

Table 4. Differences in constituents of chews in subjects with and without precancer lesions

\begin{tabular}{|c|c|c|c|c|c|c|c|c|}
\hline \multirow[t]{2}{*}{ Precancer Lesion } & \multicolumn{2}{|c|}{ Areca } & \multicolumn{2}{|c|}{ Tobacco } & \multicolumn{2}{|c|}{ S-lime } & \multicolumn{2}{|c|}{ Gambir } \\
\hline & + & - & + & - & + & - & + & - \\
\hline Yes & 31 & 2 & 26 & 7 & 32 & 1 & 0 & 33 \\
\hline No & 67 & 19 & 47 & 39 & 70 & 16 & 13 & 73 \\
\hline$p$ value & \multicolumn{2}{|c|}{0.07} & \multicolumn{2}{|c|}{0.03} & \multicolumn{2}{|c|}{0.02} & \multicolumn{2}{|c|}{-} \\
\hline
\end{tabular}


Table 5. Mean age of onset, frequency and duration of chews in subjects with and without precancer lesions

\begin{tabular}{lccc}
\hline $\begin{array}{l}\text { Precancer } \\
\text { Lesion }\end{array}$ & $\begin{array}{c}\text { Mean age } \\
\text { of onset } \\
\text { (years) }\end{array}$ & $\begin{array}{c}\text { Frequency } \\
\text { (per day) }\end{array}$ & $\begin{array}{c}\text { Duration } \\
\text { (minutes) }\end{array}$ \\
\hline Yes & 25.80 & 5.20 & 8.10 \\
No & 26.80 & 4.20 & 8.20 \\
$p$ value & 0.66 & 0.09 & 0.62 \\
\hline
\end{tabular}

quid without tobacco is small. In Maharasthra (23), 28\% chewed with tobacco and $0.6 \%$ chewed without tobacco in their quid. Mehta et al. (23-24) reported that the betel quid chewing habit is usually the habit of chewing betel quid with tobacco; $92-98 \%$ of chewers who did not smoke included tobacco in their quid. In Cambodia (25) 3 out of 102 elderly Cambodian women did not include tobacco in their quid. In contrast, in Guam, Taiwan and Hainan, China areca nut is chewed alone or with betel leaf but tobacco is not included.

The age of onset of the chewing habit in this 6 estates is somewhat later as compared to the Yorkshire (18) study where age of onset ranged from 3 to 35. Mahmood, Jaffery, Samiuddin et al. reported a comparable finding amongst 10,749 low socio-economic people of of Karachi; majority starting the habit after the age of 20 years with a substantial number having started it between age 10-19 (26). In contrast, in the Lahu and Karen tribes in Thai, the habit of chewing was taken up later between the ages of 20 and 30 (10).

In this study, family and friends are the most significant reasons for starting of the habit; this is in agreement with findings of an intervention study (27) where tobacco use was learned from parents, elders and peers. The reasons why the Bangladeshi women in Yorkshire (18) use pan are similar to the reasons (force of habit, perception of increased work capacity and gratification) commonly cited for continuing to chew in this study.

The mean frequency of chewing is 4.5 times per day. This is lower than that in the Yorkshire (18) study where more than $65 \%$ of women consume more than 5 quids daily.

\section{CONCLUSION}

The high prevalence of the betel quid/ tobacco quid habit in estate Indians is confirmed. The young age at which exposure/initiation to the habit (10years) is identified. The major role that family and friends play as reasons for picking up the habit is also identified. Practises of adding tobacco and lime appear to have adverse effects; additions of these two constituents to the quid is associated with higher occurrences of precancer lesions and the differences are of statistical significance.

\section{RECOMMENDATIONS}

From this study, the recommendations that can be made are that health education interventions for primary prevention should be:

- targeted at younger age groups that is starting from primary schools,

- aimed at dissuading the family and community to pass on the trait / habit, and

- focused on constituents which have adverse effects

\section{ACKNOWLEDGEMENT}

This project was funded by IRPA grant IMR 94-68. The authors wish to thank the DIRECTOR, Institute for Medical Resarch, for his permission to publish the findings of this study. The authors are also grateful to Dr. Tee E Siong, Head, Division of Human Nutrition as well as the staff of the Division of Human Nutrition and the Division of Stomatology, Institute for Medical Research, for their assistance in the conduct of this study.

\section{REFERENCES}

1. Proceeding Editorial. Proceedings of the workshop on lesions associated with betel quid \& tobacco chewing habits with special consideration on betel chewers' mucosa. Dental Journal of Malaysia 1997; 18(1\&2): 6-8.

2. IARC (1985) International Agency for Research on Cancer. Monographs on the evaluation of the Carcinogenic risk of chemicals to humans: tobacco habits other than smoking; betel-quid and areca nut chewing; and some related nitrosamines.

3. National Institutes of Health. Health Implications of smokeless Tobacco use. National Institutes of Health consensus Development conference Statement. Vol. 6. No. 1,1986.

4. World Health Organization. Control of oral cancer in developing countries: Report of WHO meeting. Bull Wrld Hlth Organ 1984; 62: 817-830.

5. Gupta PC, Mehta FS, Daftary DK et al. Incidence rates of oral cancer and natural history of oral precancerous lesions in a 10-year follow-up study of Indian villagers. Community Dent Oral Epidemiol 1980; 8: 287-333.

6. Gupta PC, Mehta FS, Pindborg JJ, Bhonsle RB, Murti PR, Daftary DK, Aghi MB. Primary prevention trial of oral cancer in India: a 10-year 
follow-up study. J Oral Pathol Med 1992; $21: 433-$ 9.

7. Khadim MI. The effects of pan and its ingredients on oral mucosa. J Pak Med Assoc 1977; 27: 353 6.

8. Mehta FS, Pindborg JJ, Hammer JE et al. Oral cancer and precancerous conditions in India. Copenhagen: Munksgaard, 1971.

9. Senewiratne $B$, Uragoda CG. Betel chewing in Ceylon. Am J Trop Med Hyg 1973; 22: 418-22.(16).

10. Reichart PA, Mohr U, Srisuwan S et al. Precancerous and oral mucosal lesions related to chewing, smoking and drinking habits in Thailand. Community Dent Oral Epidemiol 1987; 15: 152-60.

11. Maher R. Chewing of various types of quid in Pakistani population and their associated lesions. Dent J Malaysia 1997; 18 (1\&2): 12-15.

12. Murti PR, Gupta PC, Bhonsle RB. Betel Quid and other smokeless tobacco habits in India: Oral Health Consequences. Dent J Malaysia 1997; 18 (1\&2): 1622.

13. Awang MN. Betel quid and oral carcinogenesis. Sing Med J 1988; 29: 589-93.

14. Ramanathan K, Canaganayagam A, Tan CK, Ratnanesan A. Frequency of oral precancerous conditions in 407 Malaysians with correlation to oral habits. Med J Mal 1973; 27: 173-81.

15. Ramanathan K, Tan CK. Ratnanesan A, Canaganayagam A. Oral precancerous condition frequency in 1648 Malaysians with correlation to oral habits. Dent J Mal Sing 1973; 13: 11-21.

16. Zain $\mathbb{R B}$, Ikeda $\mathrm{N}$, Yaacob MBH. Oral mucosal lesions surveyof adults in Malaysia. Ministry of Health Malaysia, University of Malaya and Achigakuin University Japan, IOE Petaling Jaya, October 1995.

17. Ramanathan $\mathrm{K}$ and Lakshimini S. Oral carcinoma in Peninsula Malaysia: Racial variations in the Indians, Malays, Chinese and Caucasians. Gann Monograph on Cancer Research, 1976; 18: 27-36.
18. Summers RM, Williams SA and Curzon MEJ. The use of tobacco and betel quid ('pan') among Bangladeshi women in West Yorkshire. Commun Dent Health 1994; 11: 12-16.

19. Gupta PC, Mehta FS, Pindborg JJ, Aghi MB, Bhonsle RB, Daftary DK, Murti PR, Shah HT. Intervention study for primary prevention of oral cancer among 36000 Indian tobacco users. Lancet, 1986; $1: 1253-9$.

20. Ikeda N, Handa Y, Khim SP, Durward C, Axell T, Mizuno T, Fukano H, Kawai T. Prevalence study of oral mucosal lesions in a selected Cambodian population. Community Dent Oral Epidemiol 1995; 23: 49-54.

21. Rahman ZAA, Zain RB, Ikeda N, Razak IA, Aung $\mathrm{S}$ and Abdullah F. A pilot study of oral mucosal lesions among Sarawak indigenous people. Dent J Malaysia 1997; 18(1\&2): 26-9.

22. Warnakulasuriya S. The role of betel-quid in oral cancer carcinogenesis. Dent J Malaysia 1997: 18(1\&2): 30-37.

23. Mehta FS, Pindborg JJ, Gupta PC, Daftary DK. Epidemiology and histologic study of oral cancer and leukoplakia among 50,915 villagers in India. Cancer 1969; 24: 832-49.

24. Mehta S, Gupta PC, Daftary DK Pndborg JJ \& Choksi SK. An epidemiologic study of oral cancer and precancerous conditions among 101,761 villagers in Maharashtra, India. Int J Cancer 1972; 10: $134-141$.

25. Reichart PA. Betel chewer's mucosa in elderly Cambodian women. J Oral Pathol Med 1996; 25: 367-70.

26. Mahmood Z, Jafferey NA, Samiuddin M, Malik S, Qureshi SA : Dietary and other habits of people of Karachi. Journal of Pakistan Medical Association 1974; 26:111-229.

27. Gupta PC, Mehta FS, Pindborg JJ, Aghi MB, Bhonsle RB, Daftary DK, Murti PR \& Shah HT. Intervention study for primary prevention of oral cancer among 360000 indian tobacco users. Lancet 1986; 1233-39. 